\title{
ABORDAGEM A MULHERES EM SITUAÇÁO DE VIOLÊNCIA SEXUAL NA PERSPECTIVA DA BIOÉTICA
}

\author{
Daiane Trentin 1 , Mara Ambrosina de Oliveira Vargas², Denise Elvira Pires de Pires², Fernando Hell- \\ mann ${ }^{3}$, Laura Brehmer ${ }^{4}$, Sandra Cézar Leal ${ }^{5}$
}

\begin{abstract}
Resumo: Estudo qualitativo, exploratório e analítico, com objetivo de investigar como os profissionais realizam a abordagem a mulheres em situação de violência sexual, na perspectiva da Bioética de Intervençáo. Os participantes da pesquisa foram profissionais da equipe multiprofissional que compóe o fluxo intersetorial de atendimento a mulheres em situaçáo de violência sexual, em um município localizado na regiáo centro-norte do Rio Grande do Sul, Brasil. Os dados foram coletados a partir de entrevistas semiestruturadas, realizadas no período de janeiro a abril de 2016. A amostra foi composta intencionalmente, totalizando 30 profissionais, dentre eles advogado, assistente social, enfermeiro, médico, psicólogo e técnicos. A análise de dados foi orientada pela Análise de Conteúdo Temática. Dos resultados surgiram cinco categorias: Comprometimento profissional; Envolvimento além do âmbito profissional; Trabalho em equipe; intersetorialidade e instrumentalização profissional. A equipe multiprofissional depara-se com desafios na abordagem devido à falta de ambiente adequado e de profissionais para contemplar a integralidade do atendimento, assim como com déficits no próprio preparo do profissional. Persiste a subnotificação dos casos e a resistência em atender casos de violência sexual. Considera-se que Bioética de Intervenção respalda açôes interventivas de modo a transformar o contexto e promover melhorias na abordagem a mulher em situação de violência sexual, destacando-se a urgência de políticas públicas e leis verdadeiramente efetivas para a proteçáo da mulher. A formação continuada e a instrumentalização dos profissionais são estratégias possíveis para atingir esta imagem-objetivo.
\end{abstract}

Palavras-chave: violência contra a mulher, violência sexual, bioética

\section{Atención a mujeres en situación de violencia sexual desde la perspectiva de la bioética}

Resumen: Estudio cualitativo, exploratorio y analítico con el objetivo de investigar cómo los profesionales realizan la atención a las mujeres en situación de violencia sexual, desde la perspectiva de la Bioética de Intervención. Profesionales del equipo multidisciplinar y intersectorial de atención a mujeres en situación de violencia sexual, en un municipio de la región central norte de Rio Grande do Sul, Brasil, fueron participantes de la pesquisa. La recogida de datos fue mediante entrevistas semiestructuradas, realizadas de enero a abril de 2016. La muestra fue de 30 profesionales: un abogado, un trabajador social, enfermera, médico, psicólogo y técnicos. El análisis de los datos fue guiado por el referencial del Análisis de Contenido Temático. De los resultados surgieron cinco categorías: Compromiso Profesional; Atención más allá del nivel profesional; Trabajo en equipo; Intersectorialdad y Educación profesional. El equipo enfrenta desafíos en la atención por carecer de un espacio adecuado y de la cantidad necesaria de profesionales para una atención integral, así como déficits educacionales en la preparación del profesional. Persiste el subregistro de los casos y la resistencia de algunos profesionales en atender las mujeres en situaciones de violencia sexual. La Bioética de Intervención apoya acciones de intervención para transformar el contexto y promover mejoras para la atención de mujeres en situaciones de violencia sexual, destacando la implementación efectiva de las políticas públicas, leyes y normas, y educación continua para superar las dificultades identificadas.

Palabras clave: violencia contra la mujer, violencia sexual, bioética

\section{Attention to women in the situation of sexual violence in the bioethics perspective}

\begin{abstract}
A qualitative, exploratory and analytical study, with the objective of investigating how the professionals approach the women in situations of sexual violence, from the perspective of Bioethics of Intervention. The study was carried out with the members of the multiprofessional and intersectoral team that provide care to women in situations of sexual violence in a municipality located in the central-north region of Rio Grande do Sul, Brazil. Data collection was performed through a semistructured interview between January and April 2016. The sample consisted of 30 professionals, including lawyer, social worker, nurse, doctor, psychologist and other professionals of the team. Data analysis was guided by the Thematic Content Analysis. The results were organized into five categories: Professional commitment; Attendance beyond the professional scope; Team work; Intersectoriality and professional instrumentalization. The multiprofessional team has difficulties in the attention because the places of attendance are not adequate and the amount of professionals to attend integrally is insufficient. There are also professionals unprepared for this type of care. Other problems are the underreporting of cases and the personal difficulties of professionals in addressing victims of sexual violence. Bioethics of Intervention supports interventions to transform reality and improve care for women in situations of sexual violence. It is necessary to implement public policies and laws to protect women and invest in continuing education of professionals. These strategies can overcome difficulties and improve the quality of care.
\end{abstract}

Key words: violence against women, sexual violence, bioethics

${ }^{1}$ Universidade Federal de Santa Catarina (PEN/UFSC). Florianópolis (SC), Brasil

${ }^{2}$ Departamento e do Programa de Pós-graduação em Enfermagem da Universidade Federal de Santa Catarina (PEN/UFSC). Florianópolis (SC), Brasil

${ }^{3}$ Departamento de Saúde Pública e do Programa de Pós-graduação em Saúde Coletiva da Universidade Federal de Santa Catarina (PPGSC/ UFSC). Florianópolis (SC), Brasil

${ }^{4}$ Departamento de Enfermagem da Universidade Federal de Santa Catarina (PEN/UFSC). Florianópolis (SC), Brasil

Correspondência: laura.brehmer@ufsc.br

${ }^{5}$ Escola de Enfermagem e do Programa de Pós-graduação em Enfermagem da Universidade do vale do Rio dos Sinos (UNISINOS). Porto Alegre (RS), Brasil 


\section{Introduçáo}

A violência contra a mulher consta no Relatório Mundial sobre Violência e Saúde da Organização Mundial da Saúde (OMS) que destaca e o adoecimento e mortes decorrentes da violência. Independente da tipologia e natureza da violência, açóes de violência tem impactos destruidores na saúde das mulheres, por isso a importância desta área(1).

Por acometer a vida e a saúde das pessoas que sofrem atos violentos, com potencial de morte e pela ampliação do conceito de saúde, que passa a considerar qualquer agravo e ameaça à vida, às condiçóes de trabalho, às relaçóes interpessoais e à qualidade de vida, a temática da violência é incluída no rol da saúde(2).

A violência sexual é um fenômeno que, na maioria das situaçóes, é envolto pela dor, pelo medo e silêncio(3). Para tanto, é imprescindível que os profissionais estejam capacitados para exercer a integralidade da atenção à saúde e mediar o acesso aos direitos da mulher, no acolhimento, nas ações de cuidado e encaminhamentos e na notificação em casos suspeitos ou confirmados, contribuindo na prevenção da violência sexual $(4,5)$. No Brasil, há um conjunto de leis, normas, políticas públicas e outras estratégias que adotam preceitos internacionais, as quais são adaptadas às particularidades regionais. Elas buscam orientar a assistência e contribuir na qualificação profissional(3).

Além da atuação dos profissionais da saúde, o atendimento em casos de violência sexual deve ser realizado por equipe multiprofissional e em rede, por ser um fenômeno de causas multifatoriais $(4,6,7)$. A rede de atendimento à mulher em situação de violência está dividida em quatro áreas: saúde, justiça, segurança pública e assistência social(8). Enfatiza-se a importância da articulação da rede intersetorial que envolve as três esferas governamentais e sociedade civil na garantia da integralidade do atendimento e para que não ocorra a revitimização da mulher (7).

A violência sexual requer no atendimento, pessoas com olhar "despido" e que transcende o ato em si, por ser cercada pelo estigma e discriminação e, na maioria dos casos, ser praticada por alguém próximo e em âmbito doméstico. Esses e outros aspectos fazem da violência sexual um fenômeno “invisível”(9). A perspicácia da equipe da saúde na detecção de casos de mulheres em situação de violência sexual contribui no rompimento da invisibilidade deste cenário(4).

$\mathrm{Na}$ área da saúde no Brasil, a equipe profissional e a organizaçáo do atendimento recebem a importante contribuição da Norma Técnica de Prevenção e Tratamento dos Agravos Resultantes da Violência Sexual Contra Mulheres e Adolescentes(6). As demais áreas integrantes do fluxo intersetorial de atendimento à mulher em situação de violência sexual também dispóem de orientaçóes como a Norma Técnica de Padronização das Delegacias Especializadas de Atendimento à Mulher (DEAMs) (4).

Este conjunto de leis e normas contribui na educação permanente e guiam os profissionais no exercício de sua função(7). As normas que regem a conduta têm objetivo de qualificar a prestação do serviço e destacam a responsabilidade do profissional no cumprimento de sua função de acordo com a ética profissional(10).

Além de um arcabouço legal, a atenção à mulher em situação de violência pode ser discutida a partir de uma perspectiva bioética. Para tanto a reflexão da Bioética de Intervenção é adequada por assumir que as questóes éticas deixam de ser algo de cunho íntimo ou restrito ao individual e adotam características coletivas e públicas(11). Nesta perspetiva, no atendimento à mulher em situação de violência sexual, o profissional deve atuar respeitando as decisóes da mulher e estimulando a busca dos seus direitos e inclusão social(12).

Em âmbito nacional, estudos(13-17) versam sobre potencialidades e dificuldades da equipe multiprofissional no atendimento nas situaçôes de violência sexual, mas é escassa a discussáo do ponto de vista da bioética. Na literatura internacional não foram encontrados estudos sobre o tema proposto.

Desse modo, sendo a mulher, em situação de violência sexual - uma pessoa vulnerada - e que necessita de uma atuaçáa profissional comprometida, interventiva e que transcenda o cotidiano do 
trabalho; constitui-se objetivo deste estudo: investigar como os profissionais realizam a abordagem a mulheres em situação de violência sexual, na perspectiva da Bioética de Intervenção.

\section{Método}

Pesquisa de natureza qualitativa, de abordagem exploratória e analítica, realizada com membros da equipe multiprofissional que compóe o fluxo intersetorial de atendimento a mulheres em situação de violência sexual, de um munícipio localizado na região centro-norte do Estado do Rio Grande do Sul, extremo sul do Brasil. Os locais selecionados foram: dois hospitais de referência, Secretaria Municipal de Saúde (SMS) que coordena o Serviço de Atendimento Especializado (SAE), Unidades Básicas de Saúde (UBS) e Estratégia de Saúde da Família (ESF); Secretaria de Cidadania e Assistência Social (SEMCAS) que coordena o Centro de Referência Especializada em Assistência Social (CREAS) e a Casa Abrigo; a DEAM; o Departamento Médico Legal (DML), Ministério Público; e os projetos de extensão da universidade local: Clínica de Prevenção, Intervenção e Acompanhamento em Situações de Violência (CEPAVI), e Prestação Jurídica e Atendimento Multidisciplinar as Mulheres Vítimas de Violência e Familiares (PROJUR/Mulher). A definição dos locais considerou a inclusão de todos os serviços do município em que as mulheres em situação de violência sexual têm possibilidade de buscar atendimento.

Os participantes da pesquisa foram membros da equipe multiprofissional que compóe o fluxo intersetorial dos locais selecionados. A amostra foi composta intencionalmente, totalizando 30 profissionais. Os critérios de inclusão dos participantes foram: profissionais de formação superior ou técnica, que tenham atendido ou atendem mulheres em situação de violência sexual, independente da idade, sexo, horário de trabalho e tempo de atuação. E os critérios de exclusão: profissionais que estavam de férias ou afastados legalmente por algum tipo de licença.

O processo de coleta de dados foi flexível e de acordo com a situação de cada local e das possibilidades apresentadas pelos participantes. Agendaram-se as entrevistas individuais, via te- lefone, as quais ocorreram de janeiro a abril de 2016. Os dados foram coletados, após a aprovaçáo pelo Comitê de Ética em Pesquisa CAAE: 50935915.9.0000.0121 e Número do Parecer: 1.353.999. A pesquisa seguiu a Resolução $n^{\circ}$ 466/12 do Conselho Nacional de Saúde que trata das Diretrizes e Normas Regulamentadoras de Pesquisa envolvendo Seres Humanos.

Os dados foram coletados por meio de entrevistas com roteiro semiestruturado. O tempo médio de cada entrevista foi de 20 minutos. As entrevistas foram integralmente transcritas. Os participantes foram identificados pela letra $\mathrm{P}$ de profissional, seguida da inicial por área de atuação: $S=S a u ́ d e$ (hospitalar e saúde pública) e $\mathrm{PAP}=$ Proteção ou Apoio Psicossocial e de um número.

A análise dos dados pautou-se na Análise de Conteúdo Temática(18). O estudo seguiu as três etapas preconizadas pela análise temática: primeira etapa (pré-análise); segunda etapa (exploração do material) e terceira etapa (tratamento dos resultados obtidos e interpretação). A organização dos dados utilizou como auxílio, após transcrição e validação de conteúdo das entrevistas pelos participantes, o software Atlas.ti 7.5.6 (Qualitative Researchand Solutions).

\section{Resultados}

Dos 30 profissionais que participaram das entrevistas, 11 eram enfermeiras/os, 6 psicólogas/os, cinco médicas/os, três advogadas/os e três assistentes social, e outras profissões de formação técnica, dois participantes. Destes, 12 são profissionais de saúde que atuam na área hospitalar e dez na saúde pública. Já na área de proteção ou apoio social foram entrevistados 8 profissionais.

O processo de análise dos dados resultou em cinco categorias relacionadas ao tema: comprometimento profissional; envolvimento além do (âmbito) profissional; trabalho em equipe; intersetorialidade e instrumentalização profissional.

\section{Comprometimento profissional}

Essa categoria retrata a competência do profissional em demonstrar a sua responsabilidade e, caso seja necessário, transcender o limite da sua função 
além da formação técnica profissional:

"Tento fazer, ter um olhar, mas não tenho olhar de psicólogo. Mesmo assim, tendo um olhar de outra profissáo, a fragilidade às vezes nos deixa com os olhos meio 'tampados', porque tu tentas não admitir como é que aconteceu aquilo e imagina[...]" (PPAP2).

"Sou precavida! Faço a notificação, passa pelo médico, passo e-mail para o conselho e para onde for necessário. Já procuramos oferecer ajuda psicológica e mesmo assim, às vezes, ainda pecamos"(PS7).

"Sou bem sincera, depende do grau de comprometimento do profissional de saúde da ESF elou UBS, que náo precisa ser enfermeiro, tem toda a equipe (médico, técnico de enfermagem, agentes de saúde)" (PS29).

Foi evidenciada, também, certa tensão vivenciada na equipe pelo pouco comprometimento de alguns profissionais. Porém, isso pode ser interpretado como uma resistência em lidar com a complexidade do enfrentamento envolvido no atendimento a mulheres em situação de violência sexual.

"Alguns profissionais não querem se incomodar. Há aquela questão: 'não vou notificar porque sei que vou me incomodar', e de fato ocorre isso (PS7).

"O problema ético é alguns profissionais se esquivarem de condutas legais que deviam ser adotadas, independente de ser adolescente ou não" (PS19).

Por outro lado, o comprometimento de alguns profissionais foi ressaltado na execuçáo de suas tarefas que, além de cumprir com seus deveres, articulam soluções para promoção efetiva dos direitos da mulher:

"Fizemos a parte de exames, a orientação da medicação e uma coisa interessante é que conseguimos vincular essas pacientes [...] (PS17).

"Ela veio, eu estava em atendimento, foi feito o acolhimento mesmo que o meu horário seja complicado para encaixar, mas a prioridade foi dela [...]" (PS21).

"O pessoal da área da saúde é bem engajado nisso.
Com todas as dificuldades que enfrentam, quando se trata desse tipo de situação é feito um empenho para superar as dificuldades que as instituiçôes têm" (PPAP30).

Outro aspecto notório nas falas é a importância do conhecimento do profissional que subsidia suas açóes com segurança e que estas são base para promover intervençóes do Estado na implementação de medidas no enfrentamento da violência sexual contra a mulher:

"Temos que estudar, saber da Lei. Mas aqui tenho que trabalhar, articular de uma maneira que elas não me vejam só como técnica, mas como alguém interessada em ajudar, em amenizar" (PPAP2).

"O profissional que está atendendo, deve saber que não está fazendo um Boletim de Ocorrência, que é para fins epidemiológicos. Como o Ministério da Saúde vai propor alguma intervençáo ou investir [...] Há invisibilidade de todos os agravos e agora da violência, é muito mais negligenciado e omitido pelas vitimas e pelos profissionais" (PS24).

\section{Envolvimento além do (âmbito) profissional}

As falas que revelam o envolvimento profissional trazem nas entrelinhas o sentimento de estar imerso na situação a ponto que o agir ultrapassa o dever e o compromisso. Muitas vezes, isso se expressa no sofrimento do profissional, frente a essa demanda.

"Não se trata de dificuldades, porque acabamos ficando calejado quanto a isso. Não é uma função difícil, mas é dolorosa" (PPAP30).

"Controlar nossos próprios medos e anseios diante de uma situação tão difícil e conviver com isso, parecer ser forte frente a quem precisa desta ajuda" (PS16).

"Acho que me envolvo muito, até depois de todos os encaminhamentos possiveis, fico com aquela sensação de que faltou algo e poderia ter feito um pouco diferente. [...]" (PS7).

"Já acolhi mulheres vitimas de violência dentro da minha casa que nem conhecia. Não vou deixar alguém sofrer violência porque tenho medo dela. A situação dela é frágil e nós precisamos ajudar" (PPAP18). 
Essa categoria ultrapassou os limites do compromisso profissional. Corresponde à interface entre a subjetividade da vítima confrontada com a subjetividade do profissional. Um movimento de admirar-se, olhar para si através da experiência do outro e buscar acolher como gostaria de se sentir acolhida.

\section{Trabalho em equipe}

O ofício próprio de cada membro da equipe desenvolvido na perspectiva do trabalho em conjunto soma forças, compartilha conhecimentos, agiliza o atendimento e qualifica a assistência:

"O enfermeiro está fazendo o teste rápido e se deu conta que tem alguma situação que não está bem e chama o psicólogo para fazer uma escuta. Isso tem funcionado bem"(PS6).

"Por estarmos inseridas no contexto e trabalharmos com o conselho tutelar, a delegacia, conhecermos enfermeiros, médicos, assistentes sociais, facilita o trabalho"(PPAP8).

"Aqui trabalhamos em equipe: o médico, o enfermeiro, o psicólogo, o odontólogo, enfim, o que precisar de suporte da equipe" (PS10).

"Para a rede funcionar devemos conhecer as próprias entidades para saber quem pode ajudar naquele momento, porque a violência contra a mulher é multifatorial. Não é um profissional que vai melhorar aquela situação, é um conjunto de profissionais" (PPAP28).

Se, por um lado, o trabalho em equipe é reconhecido, há outras falas que demonstram dificuldades, sinalizando que a falta do mesmo impacta no atendimento às mulheres em situação de violência sexual:

"É uma questão de ética entre equipe, não é porque vi ou ouvi na recepção, que tenha que sair espalhando [...] Por mais que façamos a nossa parte, não vejo grandes progressos percebendo o desgaste que é para nós contratar pessoas desqualificadas para o serviço" (PS7).

"Mesmo com muitas pessoas para diversos atendimentos, a unidade tem outros profissionais que fazem parte da equipe e que podem qualificar o serviço como o psicólogo e o técnico de enfermagem"(PS24).

\section{Intersetorialidade}

A parceria entre as instituiçóes é uma maneira de fazer com que o atendimento à mulher em situaçáo de violência sexual ocorra na perspectiva de rede, com a articulaçáo das instituições. O trabalho em parceria reúne pessoas ou grupos afins que buscam a concretização de um objetivo comum, de sensibilizar a sociedade e aperfeiçoar os serviços em relação à violência sexual:

"Essa atuação se fortalece na medida em que chamamos essas pessoas para trabalhar junto. Promovemos momentos de capacitação e palestras para a comunidade. Isso tem ajudado bastante" (PPAP8).

"Nas escolas trabalhamos bem. É um trabalho que fazemos em conjunto com a [...] e é falado muito sobre a prevenção [...] Temos esse entendimento e fazemos seminários, buscamos parcerias" (PPAP18).

\section{Instrumentalização profissional}

O profissional instrumentalizado no que está fazendo tem segurança na abordagem e resolutividade no atendimento. $\mathrm{O}$ instrumental aqui significa o conjunto de saberes e práticas necessários para uma atuaçáo resolutiva, com qualidade para as vítimas, bem como para o enfrentamento pessoal destes profissionais. Este apontamento justifica a formação contínua do profissional como uma das prioridades, dentre os desafios neste âmbito do cuidado em saúde.

"Explicar o que pode acontecer com a medicação, qual é a possibilidade de adoecer ou de ter os exames negativos. É bem complicado, mas com a prática se torna mais fácil" (PS17).

"Caso eu não consiga de uma maneira, a experiência me fez adquirir alternativas para esse atendimento" (PS19).

"No início da minha atuação profissional ficava cheia de medos. É o que vemos, por exemplo, quando a acadêmica de enfermagem ou quem inicia o processo de acolbimento com dificuldade porque não está familiarizado"(PS21).

Nas falas a seguir sinalizam a preocupação de que 
profissionais com frágeis conhecimentos na área comprometem a abordagem qualificada:

"O profissional que não está preparado para isso, às vezes não dá a devida importância [...] Não é assim, sabe-se que as complicaçôes são bem maiores"(PS9).

"Outra dificuldade é a falta de preparo dos profissionais que atendem essas pacientes [...] ela está numa situação exposta e acaba indo para um local onde as pessoas não estão preparadas para atender" (PS17).

\section{Discussáo}

O estudo mostra o comprometimento profissional, nos diferentes serviços de atendimento à mulher em situação de violência sexual. Existe a preocupação em desenvolver a sua atividade e também de preencher eventuais lacunas na abordagem durante o atendimento, por conta da insuficiência de algumas profissóes.

Há frequentes tentativas de promover a integralidade no atendimento à mulher, mesmo que por vezes os profissionais se sintam aquém de sua atuação, há a busca desses por atender a mulher e dar o melhor de si(19).

O dever de bem atender e suprir a dificuldade da falta de certas categorias de profissionais, na abordagem, é de todos os membros da equipe e que isso depende da pessoa assumir o compromisso de atuar de maneira que possibilite o acesso ao serviço e que este contemple todas as necessidades da mulher. É compromisso, inclusive ético, da equipe multiprofissional, assumir a responsabilidade pública no que tange a execução das políticas instituídas. Um estudo realizado com profissionais odontólogos mostra essa aproximação do profissional e a responsabilidade no atendimento qualificado às pessoas na perspectiva ética(20).

Outro estudo analisou a percepção dos profissionais de uma rede intersetorial referente ao atendimento a mulheres em diversas situações de violência e apontou um distanciamento entre as políticas de enfrentamento e a realidade encontrada. Há a percepção dos profissionais dos diferentes serviços da rede, como delegacias e assistência social, da necessidade de humanizar os atendimentos e a articulaçáo dos serviços da rede(21).
Destacou-se nos resultados a preocupação com a dimensão psicológica da mulher, essa dimensão sofre impactos violentos, com sequelas que por vezes permanecem para sempre. Estudos mostram que a saúde reprodutiva, física e, sobretudo, a emocional e psicológica da mulher, é comprometida pela violência sexual, sendo necessário e indispensável o acompanhamento integral da mulher e principalmente o psicológico(22-24).

Ainda para organizar os atendimentos foi evidenciado a elaboração de protocolos, pois favorece o atendimento rápido, auxilia o profissional nas orientaçóes e encaminhamentos pertinentes nos casos de violência sexual. Os benefícios dos protocolos são demonstrados em um estudo e como esses são importantes colaboradores da equipe multiprofissional(16).

Os participantes deste estudo apontaram as dificuldades encontradas na equipe multiprofissional, justamente porque alguns profissionais não assumem o compromisso inerente de sua profissão e remetem a uma determinada categoria o atendimento. Talvez a complexidade em que consiste a violência sexual e a demanda por capacitação sejam fatores que repercutem na resistência de alguns profissionais atenderem esses casos. Estudos mostram que barreiras encontradas como formação e despreparo dos profissionais, insegurança e excesso de atividades, impactam no atendimento à mulher em situação de violência sexual e podem acarretar na revitimização da mulher $(25,26)$.

A área da saúde é multiprofissional e de múltiplos saberes. A falta de algumas especialidades profissionais para contemplar o atendimento integral em casos de violência sexual é uma questáo evidenciada em âmbito nacional e internacional, em que outros profissionais dentro das equipes de saúde ultrapassam as fronteiras de sua profissão para preencher as lacunas do atendimento especializado no cuidado e atendimento às necessidades das pessoas $(27,28)$.

Essas dificuldades também são experimentadas nas áreas de assistência psicossocial, de segurança pública e judicial. Compostas por equipe multiprofissional que têm a preocupação de prover atendimento especializado e humanizado. Entretanto, constatam a fragmentaçáo no atendimen- 
to, por conta da falta de profissionais ou serviços especializados como, por exemplo, de um Juizado Especializado em Violência Doméstica e Familiar Contra Mulheres(21). A assistência social constitui um setor imprescindível na articulação dos encaminhamentos, assim como a proteçăo jurídica, na mediação dos direitos das mulheres.

A Bioética de Intervenção sinaliza como pauta de discussão a importância da construção de serviços públicos mais acessíveis, adequados e acolhedores, capazes de promover a inclusão social e o restabelecimento da pessoa(29). Em casos de violência sexual, esta exigência se faz pertinente, pois a mulher que vivenciou ou vivencia esse fenômeno necessita de um olhar além do físico, que compreenda todas as dimensóes do ser humano e a proteçáo de seus direitos(14).

A dificuldade em notificar casos de violência sexual contra a mulher, foi um aspecto revelado pelos participantes deste estudo. A notificação obrigatória para os profissionais de saúde ou responsáveis pelos serviços públicos e privados de saúde, em casos suspeitos ou confirmados de violência contra a mulher, foi estabelecida pela Lei $\mathrm{n}^{\mathrm{o}} 10.778 / 2003$. No entanto, o Instrutivo para preenchimento da ficha de notificação de violência interpessoal/autoprovocada, recomenda que a notificação possa ser feita por Unidade de Saúde, Unidade de Assistência Social, Estabelecimento de Ensino, Centro Especializado de Atendimento à Mulher, entre outros(5). Os impasses da notificação da violência contra a mulher são relatados também em outras pesquisas(30,31).

Entende-se que o ato de notificar tem inter-relação com a Bioética de Intervenção. Demonstra o compromisso do profissional, assim como o conhecimento da legislação e todo o processo que envolve o atendimento à mulher em situaçáo de violência sexual. São as notificações que possibilitam o conhecimento do número de casos da violência sexual contra a mulher e justificam a implementação das políticas públicas e outras medidas organizadas pelo Estado e sociedade no enfrentamento desta situação. $\mathrm{O}$ ato de notificar revela-se uma ação interventiva. A "[...] ação interventiva deve ocorrer sempre a partir do diálogo com as pessoas e instituiçóes envolvidas, sejam elas destinatárias ou propositoras da ação" (32:283). Por- tanto, a notificação como intervenção não deve ser confundida com intervencionismo.

A Bioética de Intervenção propõe-se ser interlocutora entre a pessoa, a sociedade e o Estado(32). Ao analisar o profissional na perspectiva da bioética, suas açóes podem subsidiar açôes favoráveis aos vulnerados, aspecto inerente no atendimento de mulheres em situação de violência sexual, por essas constituírem-se em pessoas vulneradas, e que necessitam da promoçáo da autonomia no sentido de libertaçáo, do seu empoderamento, da sua emancipação e no direito de uma vida sem violência(33).

Outra faceta do estudo foi o envolvimento do profissional. O envolvimento foi manifestado pelos profissionais deste estudo como algo os fazem imergir na situação. A situação da violência adentra a vida do profissional, causando dor e sofrimento, pode impactar na rotina de atendimento em casos de violência sexual contra mulher. Outro impacto advém, da impossibilidade de resolução do problema da mulher pela "distância" entre o idealizado nas políticas públicas e as dificuldades do cotidiano de trabalho(34).

Tais fatores podem gerar resistência dos profissionais em atender casos de violência sexual. A dificuldade de aceitar a violência como parte integrante do atendimento em saúde, constituindo um desafio para a equipe(35). A violência sexual marca a impotência humana, despertando nos profissionais sentimentos e confrontos que podem gerar desconforto em atender casos de violência sexual por ser complexa e carregada de sentimentos que remontam a própria natureza humana de quem atende(36).

O trabalho em equipe é um aspecto positivo como mencionado em algumas falas. É uma soma de conhecimentos e partilha de experiências que dá agilidade e qualidade no atendimento à mulher em situaçáo de violência sexual(25). Logo, o acesso aos serviços da rede de atendimento e garantia dos direitos também são aspectos intrínsecos do trabalho em equipe, por conta de que a atuação da equipe na articulação dos serviços proporciona esse acesso universal e integral à mulher em situação de violência sexual(12). 
$\mathrm{Na}$ categoria intersetorialidade, contextualiza-se o movimento produzido por alguns profissionais que vai além da instituição - e acorda ao exposto: o enfrentamento da violência sexual contra a mulher é multiprofissional e intersetorial(37). É um movimento de toda a sociedade civil e governamental, envolve a sensibilização da comunidade e múltiplas estratégias pelo fim da violência. A proposta de intersetorialidade e equipe multiprofissional no atendimento também são evidenciadas em estudos internacionais $(38,39)$.

Outro aspecto do processo de trabalho evidenciado nos relatos foi a instrumentalização profissional. É possível inferir que o conhecimento acerca da violência sexual favorece a segurança dos profissionais na abordagem às mulheres vítimas. É importante conhecer e estar preparado, emocionalmente e tecnicamente, nos atendimentos de casos de violência sexual. A capacitação qualifica a abordagem dos profissionais que atuam na área da saúde(40).

\section{Consideraçóes finais}

A abordagem às mulheres em situaçóes de violência sexual, e a forma como esta é desenvolvida demonstra o comprometimento do profissional com a função assumida e prescrita nas políticas de assistência. Além disso, há o empenho subjetivo no enfrentamento das dificuldades do contexto de atendimento, principalmente com a falta de algumas categorias de profissionais.

No entanto, ainda persiste a resistência em atender casos de violência sexual e falta de preparação profissional na abordagem. A formaçáo continuada dos profissionais e a consolidação das políticas públicas na perspectiva de rede encontram respaldo na proposta da Bioética de Intervençáo. A primeira fortalece o profissional e a segunda assegura à mulher o acesso à saúde e aos direitos de proteção e apoio psicossocial. Entretanto, ambos os elementos estão interrelacionados e sáo codependentes.

O estudo anuncia uma lacuna na produção do conhecimento que articule a perspectiva bioética para reflexóes aplicadas à atenção às mulheres em situação de violência sexual. Especialmente, os preceitos da Bioética da Intervenção contribuem para orientar ações ética e profissionalmente responsáveis. 


\section{Referências}

1. Organização Mundial da Saúde. Relatório Mundial sobre violência e saúde. Genebra: Organização Mundial de Saúde; 2002.

2. Organização Mundial da Saúde. Prevenção da violência sexual e da violência pelo parceiro intimo contra a mulher: ação e produção de evidência. Genebra: Organização Mundial de Saúde; 2012.

3. Departamento de Análise de Situação de Saúde, Secretaria de Vigilância em Saúde, Ministério da Saúde. Viva: instrutivo de notificação de violência doméstica, sexual e outras violências. Brasília: Ministério da Saúde; 2011.

4. Departamento de Ações Programáticas Estratégicas, Secretaria de Atenção à Saúde, Ministério da Saúde. Prevenção e tratamento dos agravos resultantes da violência sexual contra mulheres e adolescentes: norma técnica. $3^{\text {a }}$ Ed. Brasília: Ministério da Saúde; 2012.

5. Secretaria de Vigilância em Saúde. Instrutivo para preenchimento da ficha de notificação de violência interpessoallautoprovocada. Brasília: Ministério da Saúde; 2015.

6. Secretaria Nacional de Enfrentamento à Violência contra as Mulheres. Política Nacional de Enfrentamento à Violência Contra as Mulheres. Brasília: Secretaria de Políticas para as Mulheres, Presidência da República; 2011.

7. Secretaria de Políticas para as Mulheres. Atenção humanizada às pessoas em situação de violência sexual com registro de informaçóes e coleta de vestígios: norma técnica. $1^{a}$ Ed. Brasília: Ministério da Saúde, Ministério da Justiça, Secretaria de Políticas para as Mulheres, Presidência da República; 2015.

8. Secretaria Nacional de Enfrentamento à Violência contra as Mulheres, Secretaria de Políticas para as Mulheres. Pacto Nacional pelo Enfrentamento à Violência Contra as Mulheres. Brasília: Secretaria de Políticas para as Mulheres, Presidência da República; 2011.

9. Waiselfisz JJ. Mapa da violência 2015: Homicídio de mulheres no Brasil. 1a Ed. Brasília; 2015.

10. Pires DEP, Bellaguarda MLR, Zago AT, Matos E, (orgs.). Consolidação da legislação e ética profissional. Florianópolis: Conselho Regional de Enfermagem; 2010.

11. Garrafa V, Oselka G, Diniz D. Saúde pública, bioética e equidade. Rev Bioética 2009; 5: 1.

12. Garrafa, V. Proteção e acesso à saúde com um bem social. In: Hellmann F, Verdi M, Gabrielli R, Caponi S. Bioética e saúde coletiva: perspetivas e desafios contemporâneos. Florianópolis: DIOESC; 2012.

13. Gomes N, Erdmann AL, Higashi GDC, Cunha KS, Mota RS, Diniz NMF. Preparo de enfermeiros e médicos para o cuidado à mulher em situação de violência conjugal. Rev Baiana de Enfermagem 2012; 26: 593-603.

14. Schraiber LB, D’Oliveira AFPL, Hanada H, Kiss L. Assistência a mulheres em situação de violência - da trama de serviços à rede intersetorial. Athenea Digital 2012; 12: 237-254.

15. Osis MJD, Páuda KS, Faúndes A. Limitaçôes no atendimento, pelas delegacias especializadas, das mulheres que sofrem violência sexual. BIS, Bol. Inst. Saúde 2013; 14: 3.

16. Hasse M, Vieira EM. Como os profissionais de saúde atendem mulheres em situação de violência? Uma análise triangulada de dados. Saúde Debate 2014; 38: 482-493.

17. Pereira S, Vianna LAC. Cursos de capacitação em prevenção da violência: o impacto sobre os profissionais do setor da saúde. Rev. Esc.Enferm. USP 2014; 48:315-20.

18. Minayo MCS. O desafio do conhecimento: pesquisa qualitativa em saúde. 14a Ed. São Paulo: Hucitec; 2014.

19. Lettiere A, Nakano AMS. Rede de atenção à mulher em situação de violência: os desafios da transversalidade do cuidado. Rev. Eletr. Enf. 2015; 17: 4.

20. Gomes D, Ramos FRS. O profissional da odontologia pós-reestruturação produtiva: ética, mercado de trabalho e saúde bucal coletiva. Saúde Soc. São Paulo 2015; 24: 285-297.

21. Vieira EM, Hasse M. Percepçóes dos profissionais de uma rede intersetorial sobre o atendimento a mulheres em situação de violência. Interface (Botucatu) 2017; 21: 51-62.

22. Brierley G, Agnew-Davies R, Bailey J, Evans M, Fackrell M, Ferrari G, et al. Psychological advocacy toward healing (PATH): study protocol for a randomized controlled trial. Trials 2013; 14: 221.

23. Mobasher A, Assareh M, Karamollaahi Z, Mobasher A. Personality Psychopathology Among Female Victims of Domestic Violence Referred to the Forensic Medical Center, Ahvaz, Iran. Advances in Evironmental Biology 2014; 8: $307-$ 310.

24. Oliveira PP, Viegas SMF, Santos WJ, Silveira EAA, Elias SC. Mulheres vítimas de violência doméstica: uma abordagem fenomenológica. Texto Contexto Enferm. 2015; 24: 196-203.

25. Costa DA, Marques JF, Moreira KAP, Gomes LFS, Henriques ACPT, Fernandes AFC. Assistência multiprofissional à mulher vítima de violência: atuação de profissionais e dificuldades encontradas. Cogitare Enferm. 2013; 18: 302-309. 
Abordagem a mulheres em situação de violência sexual na perspectiva da bioética - Daiane Trentin et al.

26. Barros LA, Albuquerque MCS, Gomes NP, Riscado JLS, Araújo BRO, Magalhães JRF. Vivência de (des)acolhimento por mulheres vítimas de estupro que buscam os serviços de saúde. Rev. Esc. Enferm. USP 2015; 49: 193-200.

27. Scherer MDA, Pires DEP, Jean R. A construção da interdisciplinaridade no trabalho da Equipe de Saúde da Família. Ciência \& Saúde Coletiva 2013; 18: 3203-3212.

28. OECD. Health Workforce Policies in OECD Countries - Right Jobs, Right Skills, Right Places. FOCUS ON 2016.

29. Santos IL, Shimizu HE, Garrafa V. Bioética de intervenção e pedagogia da libertação: aproximações possíveis. Rev. bioét. 2014; 22: 271-281.

30. Veloso MMX, Magalhães CMC, Dell'Aglio DD, CIR, Gomes MM. Notificação da violência como estratégia de vigilância em saúde: perfil de uma metrópole do Brasil. Ciência \& Saúde Coletiva 2013; 18: 1263-1272.

31. Sousa MH, Bento SF, Osis MJD, Ribeiro MP, Faúndes A. Preenchimento da notificaçáo compulsória em serviços de saúde que atendem mulheres que sofrem violência sexual. Rev. Bras. Epidemiol. 2015; 18: 94-107.

32. Ferreira FS, Nascimento WF. A bioética de intervenção no contexto do pensamento latino-americano contemporâneo. Rev. Bioét. 2015 Aug; 23(2): 277-284.

33. Silva LES, Drummond A, Garrafa V. Bioética de intervenção: uma prática politizada na responsabilidade social. Universitas: Ciências da Saúde 2011; 9: 111-119.

34. Gomes D, Ramos FRS. Ética e comprometimento do profissional da saúde pós-reestruturação produtiva numa região metropolitana do sul do Brasil. Interface (Botucatu) 2014; 18: 49.

35. Garbin CAS. Rovida TAS, Costa AA, Garbin AJI. Reconhecimento e notificação de violência pelos profissionais da estratégia de saúde da família. Arch Health Invest 2016; 5: 8-12.

36. Oliveira PS, Rodrigues VP, Morais RLGL, Machado JC. Assistência de profissionais de saúde à mulher em situação de violência sexual: revisão integrativa. Rev. Enferm. UFPE 2016; 10: 1828-1839.

37. Pedrosa CM, Diniz CSG, Lima e Moura VGA. O Programa Iluminar Campinas: a construção de uma política intersetorial e interinstitucional para o enfrentamento da violência como um problema social. Ciência \& Saúde Coletiva 2016; 21: 1879-1887.

38. García-Moreno C, Hegarty K, D’Oliveira, AFL, Koziol-McLain J, Colombini M, Feder G. The health-systems response to violence against women. The Lancet 2015; 385: 1567-1579.

39. Stewart DE, Aviles R, Guedes A, Riazantseva E, MacMillan H. Latin American and Caribbean countries' baseline clinical and policy guidelines for responding to intimate partner violence and sexual violence against women. BMC Public Health 2015; 15: 665.

40. Baptista RS, Chaves OBBM, França ISX, Sousa FS, Oliveira MG, Leite CCS. Violência sexual contra mulheres: a prática de enfermeiros. Rev Rene 2015; 16: 210-217.

Recebido: 27 de abril de 2017

Aceito: 29 de junho de 2017 